\title{
Grain structure formation during friction stir welding observed by the 'stop action technique'
}

\author{
P.B. Prangnell *, C.P. Heason \\ Manchester Materials Science Centre, The University of Manchester Grosvenor Street, Manchester M1 7HS, UK
}

Received 24 January 2005; received in revised form 16 March 2005; accepted 17 March 2005

Available online 10 May 2005

\begin{abstract}
Experiments have been carried out to 'freeze' the friction stir welding process by stopping the tool and immediately quenching the work piece in an Al-2195 plate welded under typical conditions. Sectioning through the 'frozen' weld keyhole with the tool in place has allowed the microstructure development, leading to the formation of the ultrafine grained nugget material, to be directly observed as fresh material encounters the deformation field surrounding the rotating pin. The grain refinement process is shown to be driven by grain subdivision at the colder periphery of the tools deformation zone, and the geometric effects of strain, which together reduce the overall high angle boundary spacing with increasing deformation. However, it also involves thermally activated high angle grain boundary migration, which increases as the temperature rises towards the tool. The higher temperature latter stages of the refinement process are closely reminiscent of geometric dynamic recrystallisation seen in high strain hot torsion experiments. The nugget grain structure has also been found to become more equiaxed and coarsens slightly, due to static annealing in the thermal wake of the tool.
\end{abstract}

(C) 2005 Acta Materialia Inc. Published by Elsevier Ltd. All rights reserved.

Keywords: Friction stir welding; Nugget zone; Dynamic recrystallisation; Aluminium alloys

\section{Introduction}

Friction stir welding (FSW) is becoming an increasingly popular method for joining aluminium alloys because it can produce welds with less distortion and superior, more reproducible, properties than can be obtained by fusion welding. Furthermore, as FSW is carried out in the solid state it avoids the problems of solidification and liquation cracking, which are inherent when fusion welding high strength $\mathrm{Al}$-alloys that have compositions with wide freezing ranges [1].

In friction stir welding a rotating mushroom shaped tool, consisting of a cylindrical shoulder and a profiled

\footnotetext{
* Corresponding author. Tel.: +44 161200 2610; fax: +44 161200 3586.

E-mail addresses: philip.prangnell@umist.ac.uk, philip.prangnell @ manchester.ac.uk (P.B. Prangnell).
}

pin (or probe), is plunged into the join line between two butted plates. The tool is then traversed under conditions where frictional heating and the plastic work rate raise the temperature of the material $\left(400-500^{\circ} \mathrm{C}\right)$ so that it can be plastically deformed at a low flow stress. The hot metal is constrained by the colder surrounding material and between the tool shoulder and a backing plate forcing it to flow around the rotating probe forming a joint [2-4]. The majority of material ahead of the tool is extruded around the retreating side of the pin, filling in the cavity to the rear of the tool. However, complex interacting flows can occur due to features machined into the pin, such as threads and flutes, which are designed to drive material downwards near the probe surface, as well as from flow under the tool shoulder [2-6]. The material that flows around the tool undergoes extreme levels of plastic deformation reaching effective strains in excess of $40[7,8]$ and this normally 
leads to a very fine $2-10 \mu \mathrm{m}$ recrystallised grain structure being formed in the centre of the weld $[9,10]$. This region of the weld is commonly referred to as the 'nugget zone' and is part of the thermo-mechanically affected zone (TMAZ) of the weld [1]. The surrounding material that constrains the nugget metal is deformed by passage of the tool and forms the remainder of the TMAZ, and experiences much lower plastic strains $\left(\varepsilon_{\text {eff }} \sim 0-5\right)[7,8]$. The grains in this region are rotated and elongated by interaction with the tool, but do not generally recrystallise $[1,11]$. Very large strains are also experienced under the shoulder contact area where fine grain structures similar to those seen in the nugget can be formed [9].

Due to its unusual ultrafine grain size, the nugget zone is an interesting feature of friction stir welds and there has been some debate as to how it develops (e.g. [11-19]). The grain structure found in FSWs is of the order of the subgrain size and cannot therefore be formed by a discontinuous recrystallisation process which would typically require large scale high angle boundary (HAGB) migration. It is thus most probably the result of a form of continuous recrystallisation. The formation of the ultrafine nugget grain structure has been widely attributed to 'dynamic recrystallisation' [11-19], although relatively little attention has been paid to the actual mechanism by which recrystallisation takes place or the fact that material first encounters the edge of the tool's deformation field at a relatively low temperature. In fact dynamic recrystallisation is rare in aluminium alloys because recovery occurs rapidly at elevated temperatures in high stacking fault energy face-centred cubic metals, lowering the driving force for recrystallisation [20]. However, few deformation studies have been carried out at the high strains rates and extreme strain levels experienced in friction stir welds.

Due to the extremely high strain levels reached in the weld nugget, several researchers have proposed that continuous dynamic recrystallisation may occur in FSWs simply by the rotation of subgrains, due to the absorption of dislocations into the subgrain boundaries, until they develop high misorientations (e.g. $[11,12,15])$. Unfortunately, such a hypothesis is not in agreement with the results of experiments from high strain torsion testing. This has consistently shown that during hot deformation of Al-alloys, under conditions where the grains deform homogeneously and do not develop significant orientation gradients, the subgrain misorientations reach a steady state of only a few degrees after an effective strain of about three and do not continuously increase to ultra high strains [21-23]. Continuous dynamic recrystallisation by progressive lattice rotation has been observed to occur at elevated temperatures in some aluminium alloys containing high solute levels, such as $\mathrm{Al}-5 \% \mathrm{Mg}$ [24]. This phenomenon is associated with materials in which restricted dislocation glide causes localised plastic deformation in a grain mantle region and the rotation of subgrains adjacent to the grain boundaries gives rise to the development of new subgrain-scale grains along the original grain boundaries [25]. A further continuous recrystallisation process that is known to produce fine grain structures in aluminium alloys at very high strains is that of geometric dynamic recrystallisation (GDR) [23,26-28]. GDR occurs when grain boundaries present during deformation start to impinge because of the geometric requirements of strain. In large strain deformation high aspect ratio fibrous grains will develop with a width that eventually approaches the subgrain size, at which point, if there is sufficient boundary mobility, the grains become unstable due to the effects of surface tension, and pinch off, breaking up into short segments. This characteristically produces fine elongated grains of the order of two to three subgrains long and one subgrain wide [23,27].

Recently, as a result of a detailed electron back scattered diffraction (EBSD) study, the process of nugget formation has also been described as one of grain subdivison induced by severe plastic deformation with dynamic recovery [29]. Grain subdivision due to texture instability is known to occur in low temperature deformation (typically less than $300^{\circ} \mathrm{C}$ [30]) and may extend to higher temperatures under the high strain rates seen in friction stir welding. Grain subdivision would certainly accelerate the rate at which boundary impingement processes like GDR can occur. However, if the mechanism of the formation of new grains involves some high angle boundary migration it is better described as a recrystallisation process. An additional possibility is that static continuous recrystallisation may occur in the trailing thermal field following formation of the weld. Work on severe deformation processing, and annealing cold friction stir welds, has clearly shown that high strain deformation structures, containing greater than $\sim 70 \%$ HAGBs will continuously recrystallise into an ultrafine grain structure on annealing $[31,32]$. Unfortunately, the extent to which any of these possible mechanisms contribute to the formation of nugget zone grain structures has not yet been conclusively demonstrated.

The nugget zone within friction stir welds also frequently contains flow features comprised of concentric 'onion' rings that correspond in width to the incremental advance of the tool per revolution [10]. The formation of these rings has been variously attributed to differences in grain size, particle density, and texture [9,33-35], but their origin has not yet been fully clarified.

Virtually all previously published results on the grain structures of FSWs have been obtained from "post-mortem' studies of completed welds. Static recrystallisation and recovery can occur very rapidly at elevated temperatures, and there is a considerable time lapse after the nugget material has been deformed until the weld has cooled, which could easily confuse microstructural 
interpretation. Furthermore, post-mortem studies do not show how the grain structure develops as the material interacts with and flows around the tool. To develop a better understanding of the formation of the unusual grain structures seen in friction stir welds, here, observations are reported on samples obtained from 'stop action welds', where experiments have been carried out to freeze the welding process by rapidly breaking the tool motion and immediately quenching the work piece. This approach has allowed the material interacting with the probe to be directly observed by sectioning through the 'frozen' weld keyhole with the tool in situ. The results presented focuses on an example weld produced under typical conditions in an $\mathrm{Al}-\mathrm{Cu}-\mathrm{Li}-\mathrm{Mg}$ alloy, AA2195, and should be seen as complementary to the work of Fonda et al. [29], who have investigated similar samples in a parallel study.

\section{Experimental}

A 'stop action' weld sample was supplied by Concurrent Technologies Corp., following an idea proposed by the author. The weld was produced in a 1 in. thick 2195 $\mathrm{Al}$-alloy plate in a proprietary under-aged temper, with a composition of $4.1 \% \mathrm{Cu}, 0.9 \% \mathrm{Li}, 0.3 \% \mathrm{Mg}, 0.3 \% \mathrm{Ag}$, $0.14 \% \mathrm{Zr}, \mathrm{Fe}+\mathrm{Si}<0.1 \%$ (wt. $\%$ ). The bead on plate weld was made using a tool with a conical threaded pin and three symmetrically opposed flat faces (see weld section in Fig. 1). The weld was produced with a spindle and

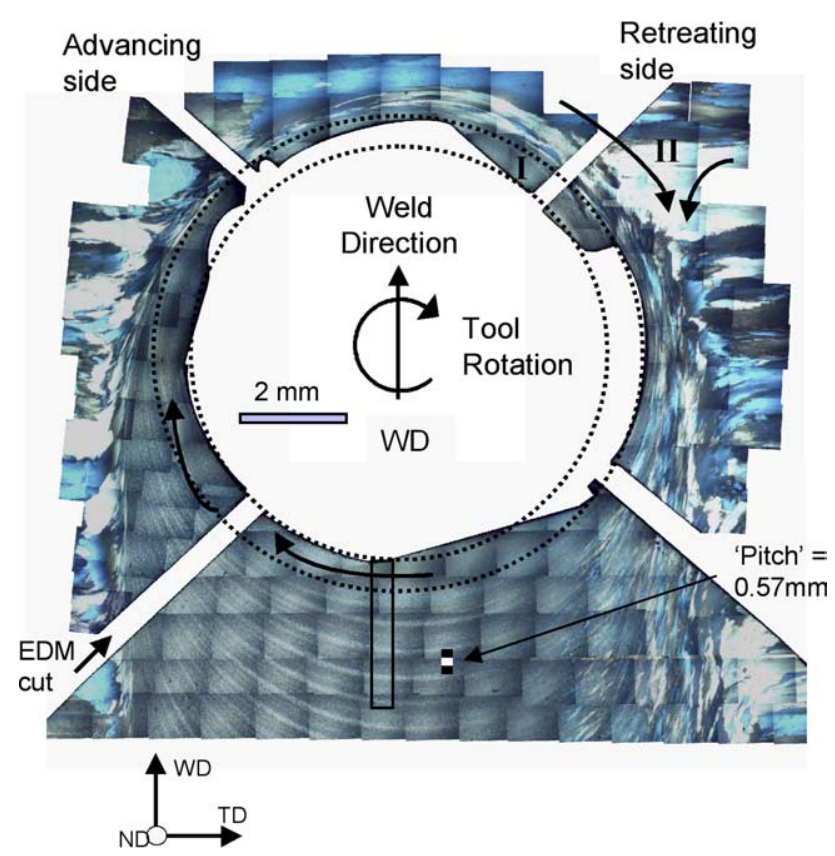

Fig. 1. Overview of the 'stop action' weld obtained from stitching together orientation contrast optical images, taken under polarized light on an anodized sample. The dashed circles indicate the pin diameter and thread depth, arrows show direction of metal flow. traverse speed of $180 \mathrm{rpm}$ and $1.7 \mathrm{~mm} / \mathrm{s}$, giving a 'pitch' of $0.57 \mathrm{~mm} / \mathrm{rev}$ (travel per revolution). When the welding head had travelled $\sim 200 \mathrm{~mm}$ the welding machine's emergency stop was engaged, which immediately removed power from the translation and spindle drives. The resistance of the work piece dissipated the momentum of the drive train and stopped the rotation of the spindle within 0.1 of a second, corresponding to $\sim 1 / 6$ of a rotation. On activating the emergency stop, water was simultaneously poured onto the work-piece to quench the plate. The plate centre cooled to less than $80^{\circ} \mathrm{C}$ within $\sim 30 \mathrm{~s}$, but importantly in the context of trying to prevent static recrystallisation, cooled much more rapidly in the critical higher temperature range of above $300{ }^{\circ} \mathrm{C}(\sim 5 \mathrm{~s})$. The weld stop position was then sectioned in thin slices through the pin using electrical discharge machining in the plane of the plate, permitting a plan view of the 'frozen' weld keyhole. Although, due to the thread, some vertical flow can occur in the weld near the pin, the majority of the deformation occurs in the horizontal plane and the sections in the plane of the plate are therefore more revealing than the traditionally used weld cross-sections presented in most postmortem studies. These slices were quartered (Fig. 1) to allow removal of the remnants of the pin, which was not strongly adhered and fell away without damaging the contact surface.

Microstructural studies focused on the slice from the centre plane of the weld to avoid the more complex flow that occurs near the shoulder and weld root. This slice was examined metallographically by optical microscopy using polarized light to obtain orientation sensitive contrast after polishing and anodizing with Barkers reagent. Higher resolution quantitative analysis was also performed by using a CamScan MaXim FEG-SEM to obtain EBSD orientation maps, after lightly electro-polishing. In the EBSD data, a lower limit boundary misorientation cut-off of $1.5^{\circ}$ was used to eliminate orientation noise. High angle boundaries were defined as being $>15^{\circ}$ in misorientation for an angle axis pair. Where shown, in the EBSD maps presented, black and light lines indicate high and low angle boundaries, respectively.

\section{Results and discussion}

\subsection{Overview of the 'stop action' weld}

An overview of the metal flow and grain structure seen in the sectioned 'stop action' weld is shown in the composite orientation contrast optical image in Fig. 1 (higher magnification images of the sectioned quadrants are shown below in Figs. 2, 4, 6 and 7). The metal flow, indicative from the grain structure in the TMAZ, is in good agreement with modelling predictions (e.g. $[7,8])$ 


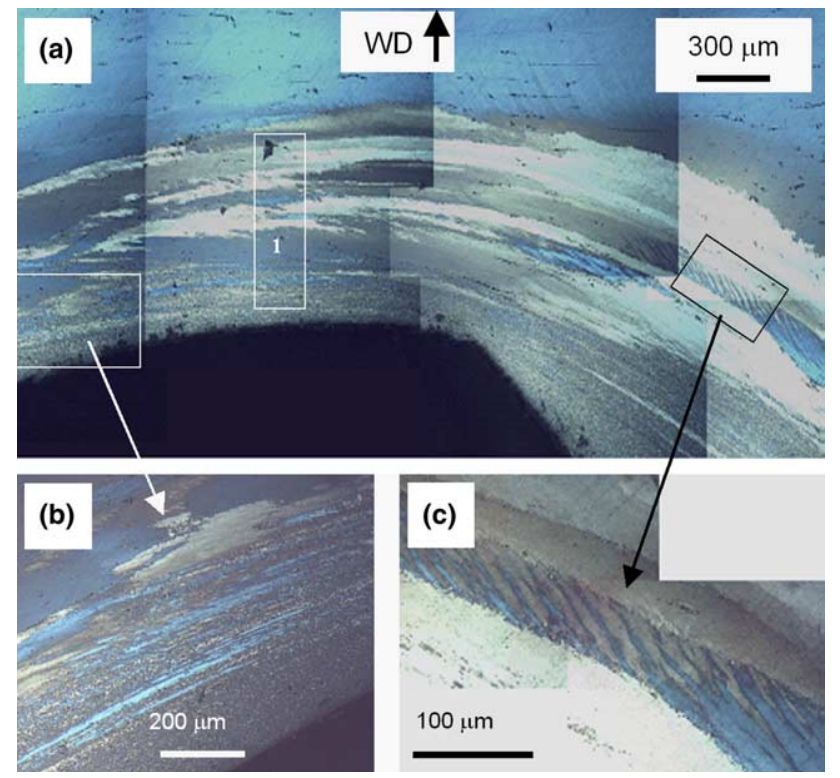

Fig. 2. Composite orientation contrast optical image of the deformation zone ahead of the pin (a), with selected areas shown at higher magnifications in (b) and (c). The white box (I) indicates the position of the EBSD map shown in Fig. 3.

and shows that grains surrounding the weld region are sheared in the same sense as the pin rotation (clockwise). On the advancing side of the weld the grains in the TMAZ are bent forwards in the welding direction and there is a sharp interface with the nugget material. Ahead of the tool there is a narrow deformation zone of grains deformed in the same direction as the tool rotation. Material ahead of the tool close to the pin flowing in the threads and at the flats within the locus of the tool diameter can be seen to have a similar ultrafine grain structure to the nugget behind the tool (e.g. I in Fig. 1). This suggests the thread and flats on the tool can trap and move some material from the rear of the pin right around the tool so that it experiences more than one rotation. Similar predictions have been made in model simulations $[8,36]$.

In comparison to the advancing side of the weld, the deformation zone (or TMAZ), on the retreating side of the pin is wider due to the clockwise rotation of the tool causing all the material displaced ahead of the pin to flow past this side of the probe. This rotational flow close to the pin meets a second flow of material past the pin from ahead of the tool to the retreating side (at (II) in Fig. 1). To the rear of the tool the nugget region is wider than the pin diameter on the advancing side of the weld, suggesting the nugget cavity is expanded by pressure from material flow caused by the clockwise rotation of the tool, while on the retreating side of the weld, the nugget zone is narrower than the pin diameter and there is a much more diffuse boarder between the nugget and the TMAZ.
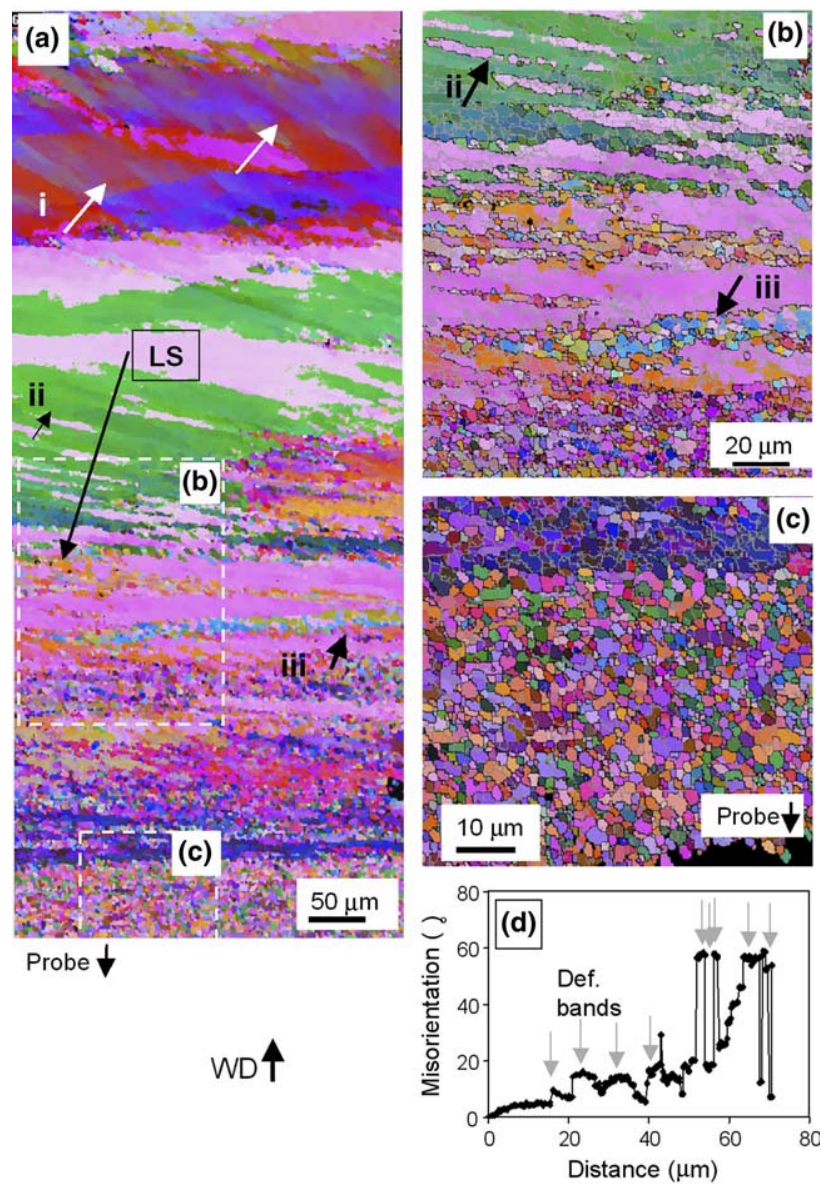

Fig. 3. EBSD map from directly ahead of the tool, showing the effect of the progressively increasing strain and temperature with proximity to the tool (a). Moving from top to bottom of the map, grains can be seen splitting into deformation bands (i) which increase in misorientation and reduce in spacing (ii) until they form finely spaced, parallel new HAGBs that then break-up along their length by thermally assisted boundary migration to form fine nugget-scale grains (iii), enlarged in (b) (see also Fig. 13). The material immediately next to the pin surface is shown in (c). An accumulative misorientation line scan along the line indicated in (a) is included in (d).

Within the fine grained nugget behind the tool distinct bands, or onion rings, can be seen, which under polarised light correspond to rings with different crystallographic orientations (discussed further in Section 3.3). These bands appear to result from the periodic flow of material around the rear of the pin and their spacing is normally found to coincide with the tool advance each revolution [10]. Here it can be seen (bottom left; Fig. 1(a)) that there is a strong ring, with a spacing that corresponds to the distance the tool moves in one full revolution $(0.57 \mathrm{~mm})$, but within this ring there are two further equispaced weaker rings. These weaker rings are related to the three flats on the tool, which disturb the metal flow every third of a revolution, while the large ring reinforces this effect every full revolution due to any non-concentricity and vibration in the welding head. 


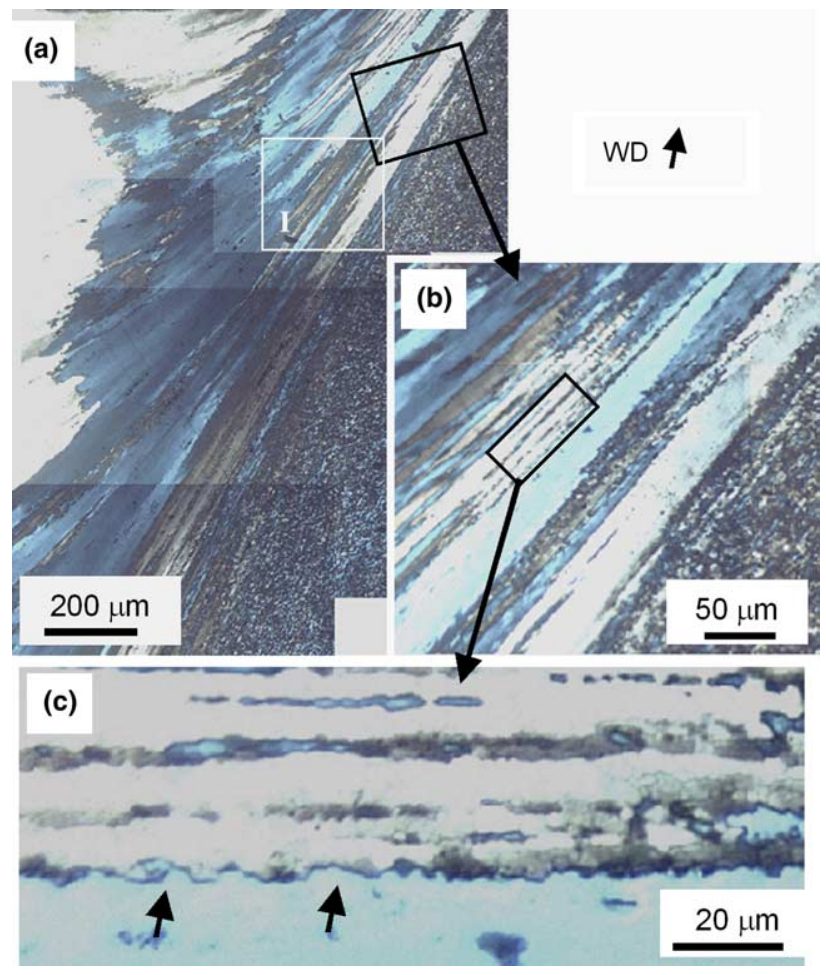

Fig. 4. Orientation contrast optical images from the advancing side of the weld at increasing magnifications. The white box (I) corresponds to the EBSD map area in Fig. 5(a).

\subsection{Grain structure evolution around the pin}

Direct interaction between the tool and weld microstructure has not been previously widely studied in FSWs. The grain structures that develop around the pin are described below in three sections corresponding to the regions; ahead of the tool, and to its advancing and retreating sides. This distinction is somewhat artificial and has been used to try to highlight examples of important features in the microstructure that can be used to interpret how the grain structure develops, and ultimately leads to the very fine grain structure seen in the weld nugget. It should be noted that there is considerable commonality between the observations in the different regions and the original coarse grains that start off on the advancing side may be sheared by the pin to finally break-up into material with an ultrafine nugget grain structure on the retreating side, or the rear of the pin. The possible mechanisms of grain refinement will be discussed further in Section 3.4.

\subsubsection{The grain structure ahead of the tool}

Magnified optical images and an EBSD map taken from the material ahead of the advancing tool are shown in Figs. 2 and 3. This region of the weld experiences the steepest thermal gradient and the plastic zone extends $<1 \mathrm{~mm}$ ahead of the tool. The microstructure shows characteristics of both cold and hot deformation, with the strain and temperature initially increasing gradually and then dramatically close to the pin. In the colder region near the edge of the deformation zone the surrounding grains can be clearly seen to be distorted and split into coarse deformation bands, as they are compressed and sheared in a clockwise direction by the advancing pin (Figs. 2(c) and 3(a); position (i)). Fig. 2(c) shows an example of an unstable grain orientation that has split into two alternating orientations. This behaviour is typical of a coarse-grained aluminium alloy deformed at relatively low temperatures $\left(<300^{\circ} \mathrm{C}\right)$ to strains of greater than $\sim 0.5[30,37]$. These deformation bands subdivide the original grains into new slab-shaped grains, which rotate towards the shear direction and reduce in width as the strain increases closer to the tool. Their reduction in spacing and increase in misorientation with proximity to the tool can be seen in the line scan in Fig. 3(d). Near to the tool, thinner fibrous grains, originating from similar deformation bands from the advancing side of the tool (Fig. 2(b)), are drawn out and become highly elongated as the strain level and temperature rapidly increases. As the temperature rises, a mixed structure of bands of fine nugget-like grains and very thin fibrous grains appears, indicating the initial stages of recrystallisation (Figs. 2(b) and 3(c)). The microstructure at this position is consistent with there being sufficient thermal energy for some localised boundary migration, in that 'wavy' HAGBs have now developed (see also Fig. 4(c) below). The material closest to the pin's outer circumference can be seen at the bottom of Fig. 3(c) and is comprised predominantly of $\sim 3 \mu \mathrm{m}$ low aspect ratio grains similar to those seen in the nugget zone at the rear of the tool (see Fig. 8(a) below). However, there are still some larger retained grain fragments containing subgrains and the HAGB area fraction is around $60 \%$.

\subsubsection{Advancing side of the weld}

On the advancing side of the weld (Fig. 4) the parent grains in the TMAZ are sheared forwards in the welding direction, due to the clockwise tool rotation. Similar effects are seen to those reported above, but are more spread out because of the shallower thermal and strain gradients. In the cooler less strained region near the TMAZ edge grains are split into coarse deformation bands (Fig. 4(a) and arrow (i) in 5(b)) which rapidly develop high misorientations (Fig. 5(c)). As the tool advances the grains, which were originally ahead of the pin, are rotated, compressed, and elongated. During this process the coarse deformation bands, that initially subdivided the parent grains into slab-shaped grains at low temperatures on the edge of the deformation zone, are drawn out to form long thin fibrous grains (Fig. 4(a) and (b)). If these grains are tracked individually in the optical orientation contrast images, as they are sheared around the pin, they can be seen to reach 

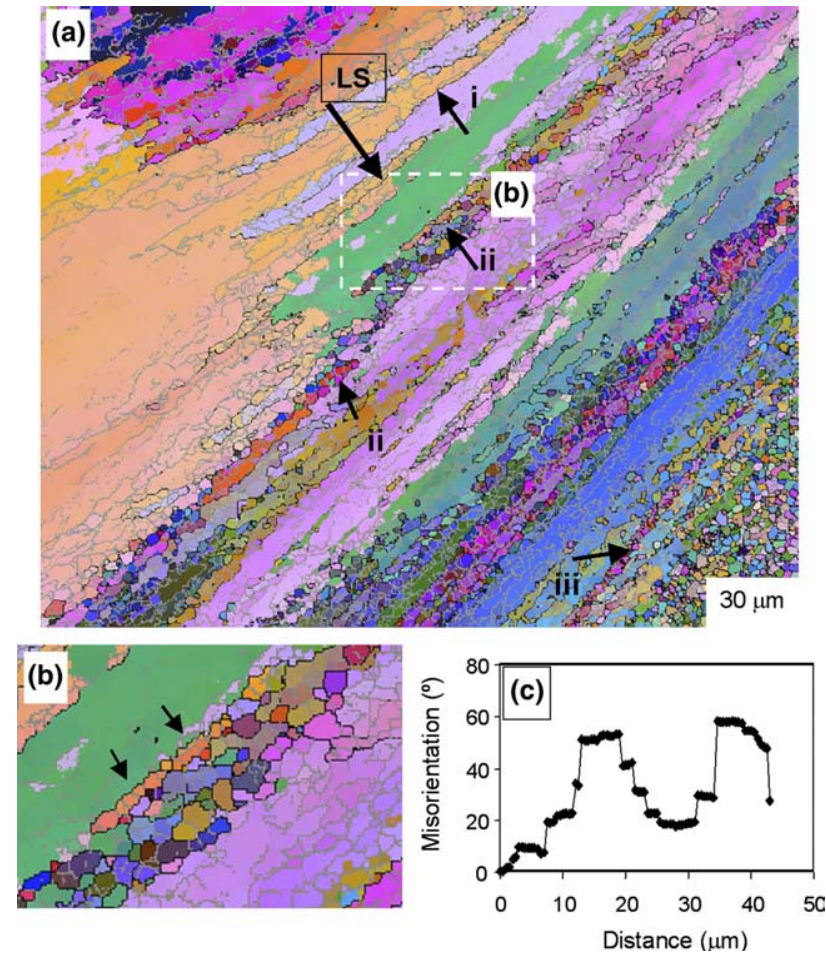

Fig. 5. (a) EBSD map from ahead of the tool on the advancing side of the weld, showing a grain splitting into deformation bands with two alternating orientations at (i) and steep orientation gradients across their borders (c) (Linescan 1). At a higher magnification in (b) bands of fine nugget-scale grains can be seen forming as the temperature and strain rises closer to the tool.

extreme aspect ratios as the shear strain and temperature increases (Figs. 1 and 4). At the edge of the tool a fully nugget-like region is seen and at its periphery there is a mixed structure, similar to that found ahead of the tool, comprised of bands of ultrafine nugget like-grains and surviving thin fibrous grains that eventually break up into fragments and evolve into the nugget-like grain structure as they are further deformed.

At higher magnifications new HAGBs originally formed by grains splitting into deformation bands, when the material was colder nearer the edge of the deformation zone, can be seen to develop wavy boundaries (Fig. 4(c)) and fine grains of a similar scale to those found in the nugget form along their borders (arrow (ii), Fig. 5(a)), as the strain and temperature increases closer to the tool. When the shear strain and temperature further increase towards the edge of the nugget-like region, continuous bands of ultrafine nugget-scale grains can be seen delineating the original deformation band/grain boundaries (Figs. 4(b) and 5(b)). Closely spaced parallel HAGBs, that formed by grain subdivision earlier during colder deformation, can be seen to break-up into strings of fine grains when they approach one subgrain wide (arrowed in Fig. 5(b)). At the same time the average width of the fibrous grain boundaries, which develop into bands of ultrafine grains, reduce in spacing due to

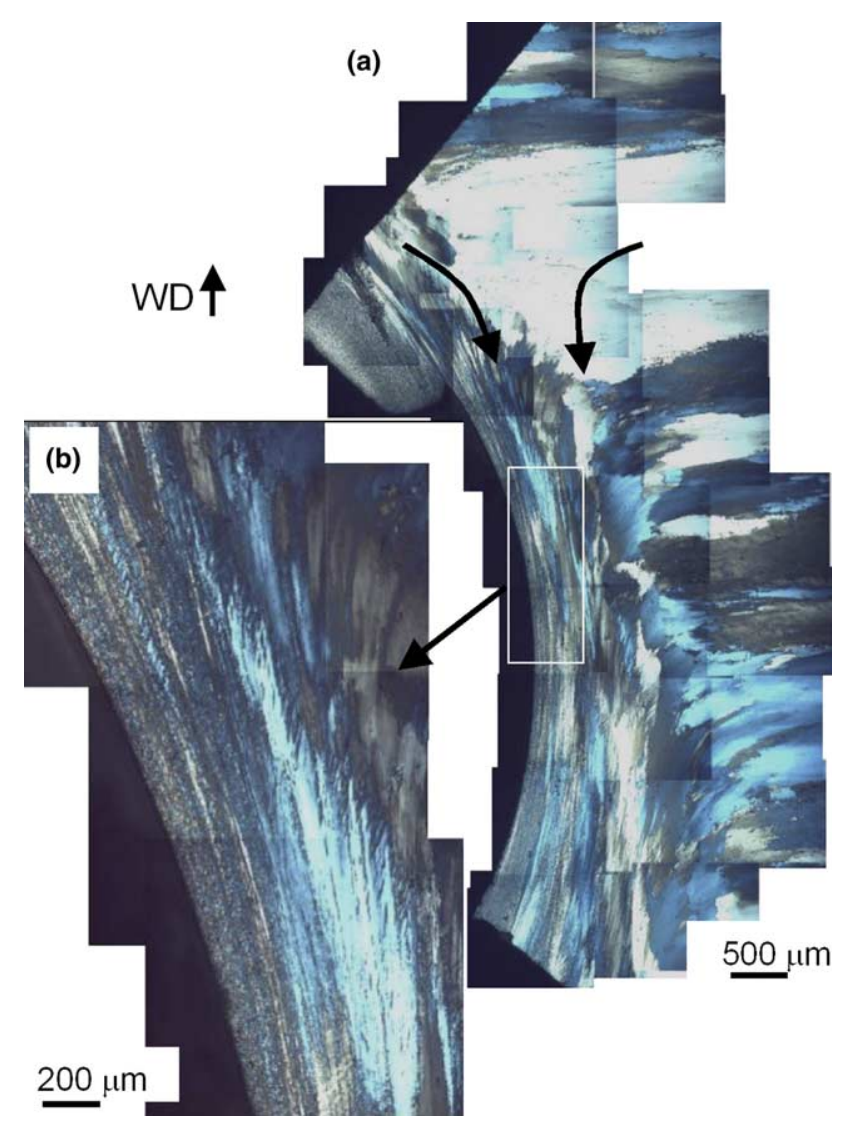

Fig. 6. Optical micrographs at low (a) and high (b) magnification from the retreating side of the pin; arrows in (a) indicate metal flow.

the increasing shear strain and closer to the pin surface the volume fraction of ultrafine nugget scale grains increases.

\subsubsection{The retreating side of the weld}

On the retreating side of the weld the deformation zone is wider than that on the advancing side, because all the material displaced by the tool is extruded around this side of the pin, driven by its clockwise rotation (Figs. 1 and 6(a)). The flow around the front of the pin of material originally from the advancing side and ahead of the tool follows an inner path close to the probe surface and meets a second flow from material ahead of the tool on the retreating side that is displaced by the pin (arrows in Fig. 6(a)). In general, the microstructure evolution shows similar features to those already described. Grains are divided into coarse deformation bands on the edge of the deformation zone, which are rotated in the direction of the tool rotation (in this case opposite to the tool travel direction) as they are forced to flow around the advancing pin. The subdivided grains increase in rotation and become thinner with higher aspect ratios as the strain increases towards the tool and this forms the microstructural gradient seen in the TMAZ, outside of the nugget region. Material that was initially ahead of the tool is found closer in 
to the pin and experiences higher temperatures and strains, which draws out the deformation bands first formed on the periphery of the deformation zone into long thin fibrous grains. Bands of new nugget-scale fine grains again form along their borders. Closer to the pin the fibrous grains, which have probably originated from as far round as the advancing side of the weld, have experienced extremely high strains and greater temperatures and thin to subgrain dimensions, within a mixed structure of bands of fine nugget-scale grains (Fig. 6(b)). Immediately next to the pin there is a narrow layer of fully refined nugget-like material.

On the retreating side of the weld, behind the tool, there is a much more diffuse boundary between the nugget and surrounding material than on the advancing side (Fig. 7(a)). This is magnified in Fig. 7(b) and can be seen to be comprised of material that has a fine nugget grain structure, blended in layers with the material that has not yet received enough strain to form a typical nugget structure until it travels further into the central region of the weld behind the pin. A similar intermittent behaviour has previously been seen in marker experiments $[3,38,39]$. This transition region may, therefore, partly be caused by an intermittent flow caused by the rotating tool facets, which mixes the rotational flow close to the pin, where a higher strain is experienced, with the flow
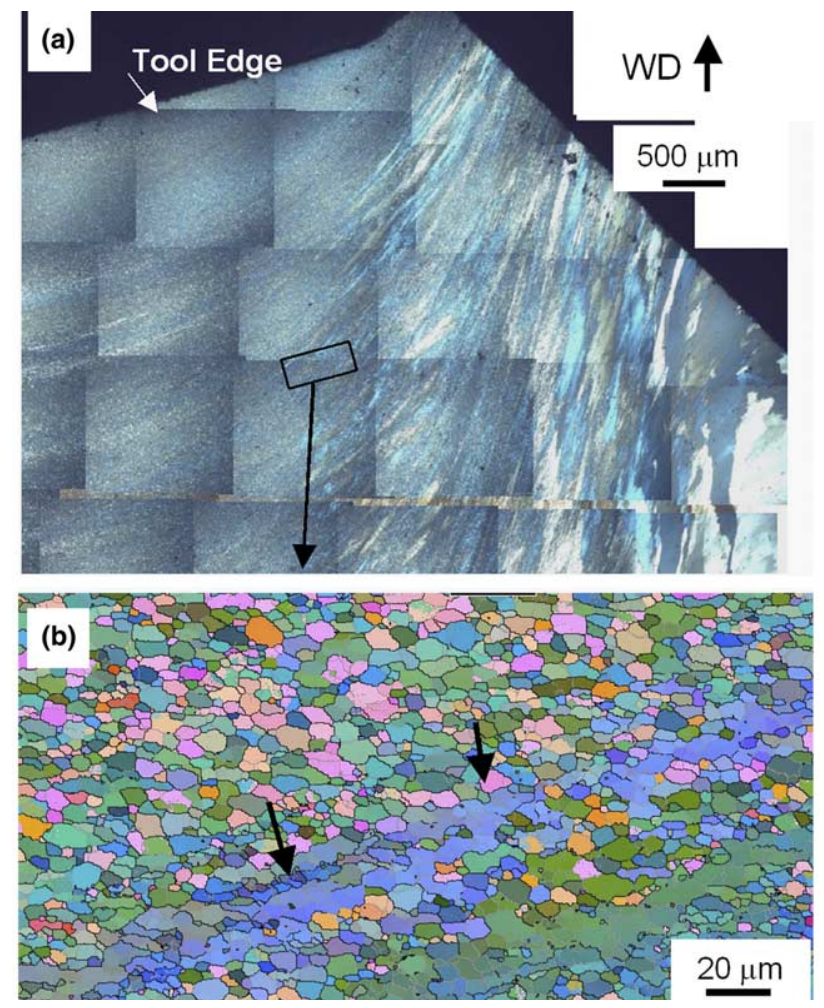

Fig. 7. (a) Optical micrograph and (b) higher magnification EBSD map from the rear of the pin on the retreating side of the weld showing the diffuse nugget boundary. past the pin as the pin cavity is filled behind the tool. However, there is also an influence of the individual parent grains which refine at different rates depending on their initial orientation (see Section 3.4).

\subsection{The nugget grain structure in the trailing weld}

EBSD orientation mapping has been used to analyse the grain structure in the nugget behind the 'stopped tool' along the weld centreline. Because the welding process was quenched, the thermal exposure will increase with distance behind the pin, due to the trailing thermal field. In Fig. 8 example EBSD maps are compared from next to the tool's surface and at 0.5 and $2 \mathrm{~mm}$ behind the pin. It can be seen that the grain structure immediately behind the pin is not as recrystallised in appearance (Fig. 8(a)) and is comprised of fine elongated fibrous
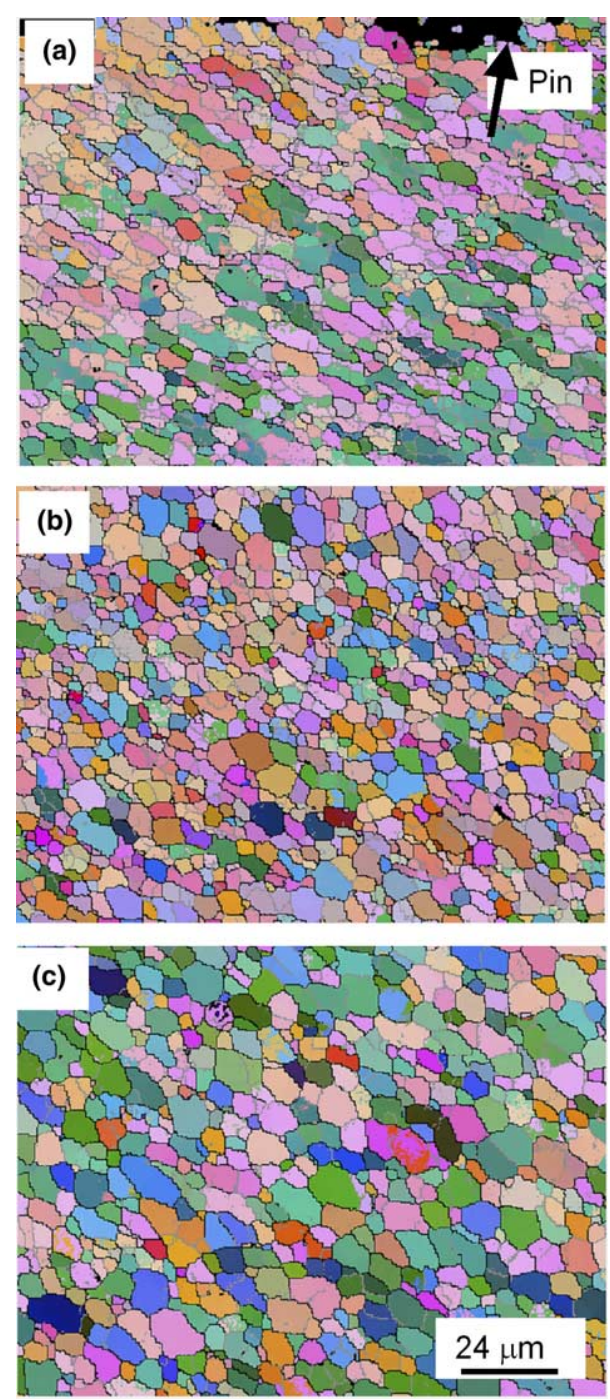

Fig. 8. EBSD maps showing the nugget grain structure along the trailing weld centreline: at (a) immediately behind the pin, (b) $0.5 \mathrm{~mm}$ behind the pin and (c) $2 \mathrm{~mm}$ behind the pin. 
grain fragments with a significant proportion of low angle boundaries ( $50 \%$ HAGB area). $1 \mathrm{~mm}$ behind the pin a more equiaxed grain structure is seen (Fig. 8(b)), typical of most nugget zone weld post-mortem studies (e.g. $[9,10,15])$, and further behind the pin a similar equiaxed grain structure is again seen, but the grains are significantly coarser (Fig. 8(c)). It should, however, be noted that there was some variability within the material immediately next to the pin surface and the map shown in Fig. 8(a), was the least recrystallised seen. The effect of the deceleration of the tool and simultaneous quenching are also difficult to determine on the grain structure of the material at the tool surface. Other areas close to the rear pin surface contained a higher fraction of HAGBs $(\sim 60 \%)$ and were more similar to that seen in Fig. 3(c).

Statistical data from similar EBSD maps are summarized in Fig. 9, as a function of distance behind the pin along the weld centreline. These results indicate that close to the pin the material is less recrystallised. The fraction of high angle boundary area (\%HAGB) rapidly increases with distance and reaches the normally observed level of $\sim 70-80 \%[9,10]$ by $\sim 0.6 \mathrm{~mm}$ behind the pin, as static annealing by the trailing thermal field results in the formation of a more recrystallised equiaxed grain structure (Fig. 8(b)). Some grain coarsening also occurs and the grain size increases slightly until $\sim 2 \mathrm{~mm}$ behind the pin, from $\sim 4-5.5 \mu \mathrm{m}$ (note the data point immediately next to the pin shows a larger 'grain size' due to the non-typical low HAGB fraction seen at this point). The changes due to static annealing of the nugget in the welds thermal wake behind the tool are therefore relatively subtle, but do appear to result in a more equiaxed and coarser grain structure.

The grain size within the nugget was reasonably uniform and where these measurements were made along the weld centreline showed no obvious correlation with

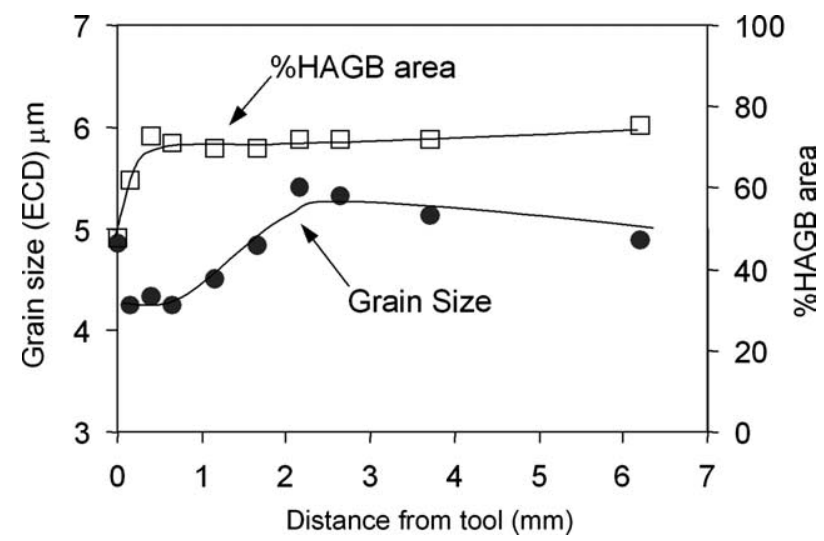

Fig. 9. The average grain size (equivalent circular diameter) and the fraction of high angle boundary area within the nugget region, measured from EBSD maps, as a function of distance behind the tool along the weld centreline. the onion rings seen in Fig. 1. To study the orientation banding seen in the nugget further, EBSD analysis was used to investigate the local texture variation within the annular rings. Most previous studies of friction stir welds have found the nugget zone to have shear textures because the deformation close to the pin is predominantly by simple shear $[29,40,41]$. Shear textures are conventionally defined in terms of the crystallographic plane $\{h k l\}$ and direction $\langle u v w\rangle$, aligned with the shear plane and shear direction, respectively $[42,43]$. In a friction stir weld the shear plane and direction are not simply related to the sample geometry, but might be expected to be approximately parallel to the pin surface, or nugget flow lines.

In Fig. 10(a) three example $\{111\}$ pole figures are shown, obtained from selected orientation bands taken from the accompanying EBSD map (Fig. 10(c)), with increasing distance behind the tool close to the weld centreline. The pole figures on the left-hand side (Fig.

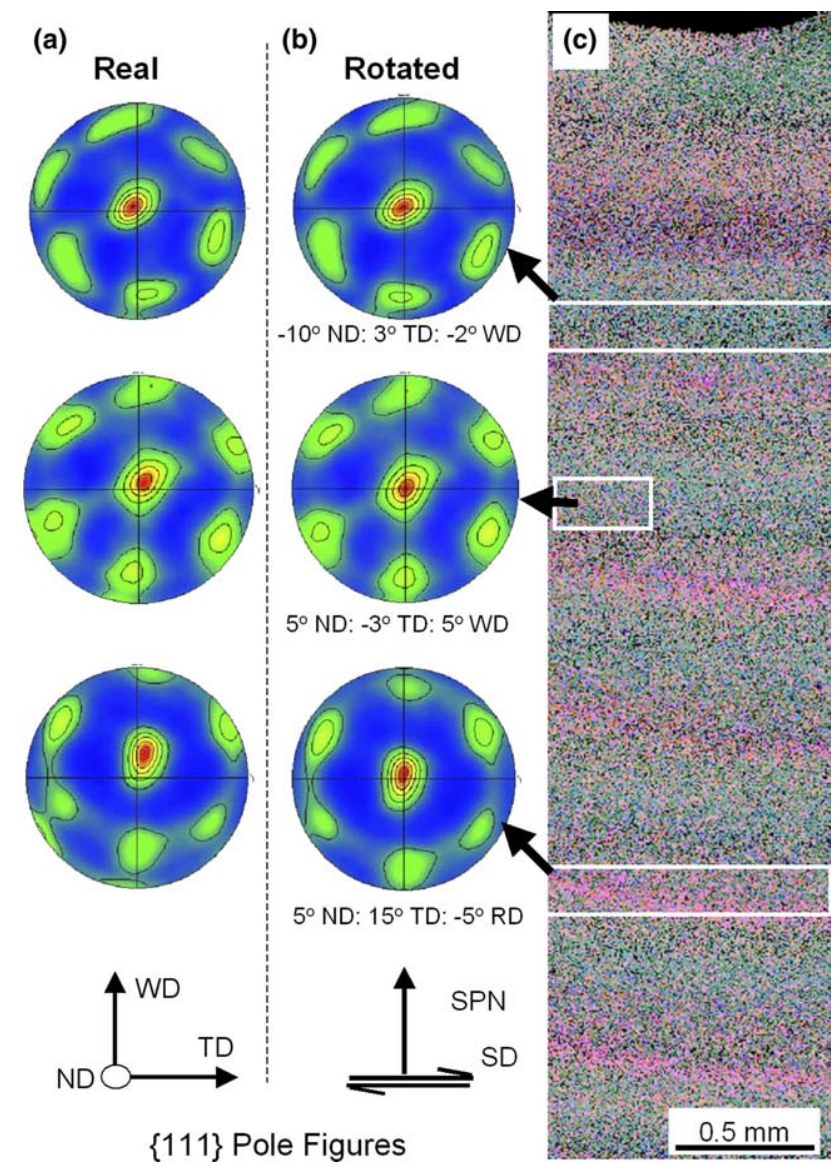

Fig. 10. $\{111\}$ pole figures showing microtextures of selected bands form within the weld nugget, at three different distances behind the pin near the weld centreline (indicated in the accompanying EBSD map). In (a) the pole figures have the same orientation as the map (i.e. from the weld mid-plane with the welding direction vertical). In (b) the pole figures have been rotated, around the axes specified, to align the assumed shear plane normal (SPN) vertical and the shear direction horizontal. 
10(a)) have not been rotated relative to the sample and have the same orientation as in Fig. 1 (i.e. from the mid-plane of the plate with the welding direction vertical). These pole figures can be described as having a prominent $\{112\}\langle 110\rangle$ shear texture, with the shear plane and direction aligned very approximately tangential to the surfaces of the nugget rings, although there was frequently some spreading of the texture around ND, which will be discussed below. In the long thin EBSD map of the weld behind the tool, from which these pole figures were obtained (Fig. 10(c)), the shear plane normal is approximately parallel to the welding direction and the shear direction lies roughly horizontal. The textures become clearer if the pole figures are rotated to present them using the conventional orientation, with the shear plane normal vertical in the plane of the page and the shear direction horizontal, as shown in Fig. 10(b). The rotations required to obtain this conventional alignment of the shear plane are given under each pole figure and are different for each area. They were typically within $10^{\circ}$ around $\mathrm{ND}$, as well as up to $15^{\circ}$ for the out of plane rotations.

The $\{112\}\langle 110\rangle$ texture results from strong symmetrically related ideal $B / \bar{B}$ orientations on the $\{h k l\}\langle 110\rangle$ $B$ partial fibre $[42,43]$. The middle example pole figure is from a smaller selected area and shows the most clearly defined $\{112\}\langle 110\rangle$ components, with a small degree of spread along the $B$ fibre. In the other pole figures (top and bottom) the texture is more noticeably spread through an arc by rotation around the ND. This strong ideal $B / \bar{B}$ orientation has previously been found in simple shear deformation of high stacking fault energy metals, like aluminium, at temperatures in excess of $400{ }^{\circ} \mathrm{C}$ [43]. It increases in intensity with strain and becomes dominant at large deformations [43]. In similar samples Fonda et al. [29] have noted a comparable texture and alignment close to the tool, which reflects a dominant simple shear deformation parallel to the tool surface, but have found that there can be a bigger spread along the $B$ fibre in regions of the weld where the strain is lower. The spreading of the texture around ND clearly reduces with the size of the area selected from the EBSD map (Fig. 10). This is because, if the shear plane/direction is aligned roughly with the surface of the pin it follows a curved surface, which causes a ND rotation, spreading the strong $\{112\}\langle 110\rangle$ component through an arc if a larger map area is selected.

The examples in Fig. 10 show that similar $\{112\}\langle 110\rangle$ shear textures are seen within different onion rings, but the shear plane/direction are slightly rotated relative to each other between bands. The nugget zone onion rings, revealed by orientation differences in the optical image in Fig. 1, are thus most probably caused by perturbations in the metal flow every time the flats machined on the tool rotate to the retreating side of the weld. This results in a rigid body rotation, between adjacent rings, which causes small misorientations of the $\{112\}\langle 110\rangle$ shear texture. Other strain components, and different strain levels, experienced by a volume of material during its passage around the tool, could also cause the texture to rotate, or alter the intensity along the B partial fibre. The observed texture variability is, therefore, not that surprising, given the complex nature of the metal flow filling the cavity behind the pin, but in general the texture in the nugget is that expected for hot simple shear deformation of aluminium alloys to high strain levels.

\subsection{Formation of the TMAZ and nugget grain structures}

In friction stir welding cold material initially ahead of the tool is heated and deformed by the rotating tool as it advances. The strain and temperature both increase simultaneously. In the typical weld sample studied, if the behaviour of an original grain in the parent material ahead of the tool is tracked, that eventually forms the ultrafine grained nugget material behind the pin, its microstructure develops in the following sequence, as it experiences increasing levels of strain and temperature and follows a flow path around the pin from the cold edge of the deformation zone, too close to the hot tool surface, and is finally deposited within the trailing weld nugget.

(i) At low temperatures near the periphery of the deformation zone the grains in the parent plate split into coarse deformation bands, commonly seen in aluminium alloys below $\sim 300^{\circ} \mathrm{C}$ at strains $>\sim 0.5-2$ [30]. This occurs in grains of orientations that are unstable within the imposed strain field and generates orientation gradients and new HAGBs at the deformation band borders (e.g. Figs. 2(a), (c) and 3(a) location (i), 4(a), 5(c)).

(ii) As the strain and temperature increases, the original grain boundaries and new deformation band boundaries rotate towards the shear direction and increase in area and reduce in separation, due to the geometric requirements of strain, forming elongated fibrous grains (Figs. 2(b) and 4(a)). Further grain subdivision occurs simultaneously with this process, on a finer scale, as different regions of grains rotate towards diverging texture orientations (Figs. 3(a) locations (i)-(ii), 3(d)). Grain subdivision will, however, reduce with increasing temperature as this will lead to more homogeneous slip.

(iii) At higher strains, the fibrous grains formed from the original subdivided parent grains increase in aspect ratio, while reducing in width. The HAGBs at deformation band/fibrous grain boundaries become wavy as the thermal energy increases and boundary migration starts to occur (Figs. 3(b) 
location (ii), 4(c)). Bands of fine nugget scale grains start to appear along the borders of some deformation bands/fibrous grain boundaries as the temperature and strain increases nearer to the pin (Figs. 3(b) and 5(b)). Closely spaced parallel HAGBs that formed by grain subdivision earlier during colder deformation (e.g. Fig. 3(b) location (ii)) break-up into strings of fine grains when they approach one subgrain wide (e.g. Fig. 3(b); location (iii), 5(b); arrowed).

(iv) With further increasing strain a mixed microstructure evolves of nugget scale grains with some retained high aspect ratio fibrous grains that have now thinned to approach a few subgrains in width (Figs. 2(b), bottom Fig. 3(b), 5; location (iii)). These retained fibrous fragments probably have more stable crystallographic orientations [29].

(v) Finally, a reasonably uniformly refined nugget-like microstructure is formed comprised of low aspect ratio fine 3-5 $\mu \mathrm{m}$ grains (e.g. Figs. 3(c) and 8(a)). The nugget grains are elongated in the shear direction with aspect ratios of $\sim 1-3$ and there is frequently a significant fraction of retained low angle boundaries (up to $\sim 40 \%$, Fig. 8 (a)).

(vi) The very fine grain structure close to the pin within the weld nugget becomes more equiaxed and coarsens slightly after deformation, due to static annealing in the tool's thermal wake. This can be accompanied by a reduction in the level of retained low angle boundaries (Figs. 8 and 9) [31]. It is, however, difficult to interpret the extent of this effect due to the delay in quenching the plate and the influence of the tool deceleration on material close to the pin.

With the addition of some static annealing in the welds trailing thermal field, (i)-(iv) above, can be satisfactorily used to explain the grain structures seen within the TMAZ, excluding the nugget formation. However, the possible mechanisms involved in the evolution of the fine-grained nugget structure deserve further attention.

\subsubsection{Mechanism of continuous dynamic recrystallisation}

It has been suggested by a number of authors that the fine nugget grain structure in FSW forms by continuous dynamic recrystallisation caused by subgrain rotation (e.g. $[11,12,15])$. This mechanism has been proposed to involve the adsorption of dislocations by subgrain boundaries, under conditions where the subgrains are pinned by second phase particles preventing growth, which increase in misorientation until they become high angle boundaries at the extremely high strain levels seen in friction stir welds. However, high strain torsion tests on aluminium alloys show that during hot deformation subgrain misorientations generally saturate at relatively low levels of $\sim 3^{\circ}$ and do not increase greatly with fur- ther strain. The increase in misorientation of a subgrain, $\theta$, due to dislocation adsorption, in a homogeneously deforming crystal, has been estimated by Pantleon [44] as a function of shear strain, $\gamma$ :

$\theta=\sqrt{\gamma b / d}$

where $b$ is the Burgers vector and $d$ is the cell size. This relationship predicts that $\theta$ increases very slowly even at large strains. For example, for a typical value of $b / d$ of $\sim 10^{-4}, \theta$ is only $3.7^{\circ}$ at $\gamma=40$, and a misorientation of $15^{\circ}$ required to form a $\mathrm{HAGB}$ is only reached at a strain approaching $10^{3}$.

Using the EBSD map shown in Fig. 3(a), $70 \mu \mathrm{m}$ long misorientation line scans have been taken transverse (along TD; see Fig. 1) to the welding direction at different distances ahead of the tool, from within stable texture bands that do not contain high densities of HAGBs formed by grain subdivision and avoiding regions closer to the tool that have already recrystallised. The average misorientations of the subgrain $\left(<15^{\circ}\right)$ boundaries along these line scans are depicted in Fig. 11(a). This data show that they only increase marginally in misorientation with distance from the tool, and hence strain, and reach a maximum of just $\sim 4^{\circ}$, similar to observations reported for torsion tests (the last line scan
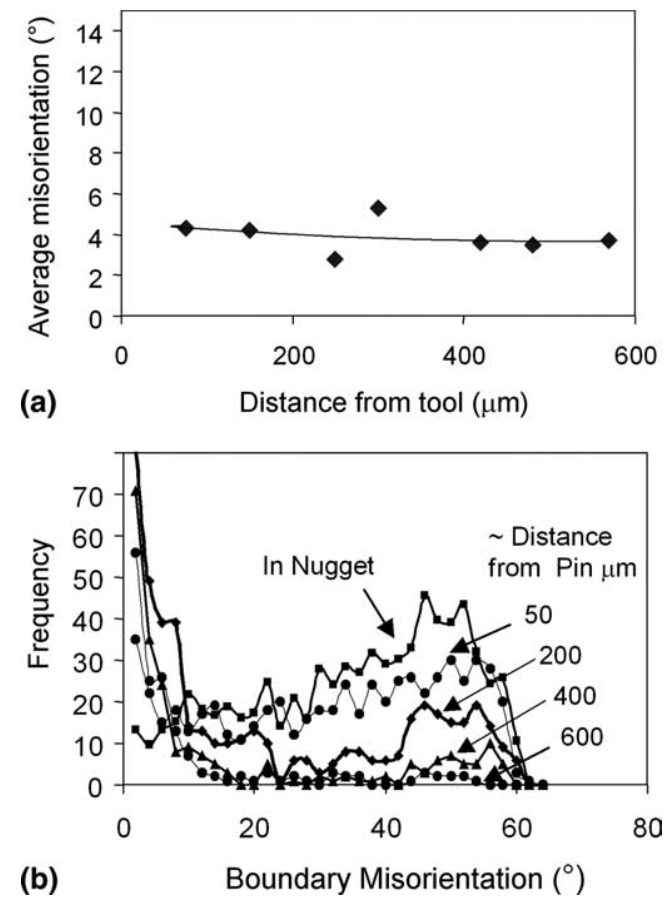

Fig. 11. (a) The average misorientations of subgrain $\left(<15^{\circ}\right)$ boundaries along $\sim 70 \mu \mathrm{m}$ long misorientation line scans, obtained from the EBSD map in Fig. 3(a), taken transverse to the welding direction as a function of distance ahead of the tool within stable texture bands and avoiding recrystallised regions. In (b) boundary misorientation distributions are shown with distance ahead of the advancing tool, taken from the same map, using selected areas of $75 \times 250 \mu \mathrm{m}$. 
closest to the tool was taken from a surviving fibrous fragment on the periphery of the nugget material).

In Fig. 11(b) boundary misorientation distributions are also shown as a function of distance ahead of the advancing tool. These distributions indicate that for low strains on the edge of the deformation zone, or TMAZ, there are mainly low angle boundaries present and the distributions shift to the right and become centred about a misorientation of $\sim 45^{\circ}$ as the strain increases closer to the tool. However, this does not occur by the whole distribution progressively moving to greater misorientations, but rather by the build-up of the frequency of boundaries with higher misorientations over a wide range from $15^{\circ}$ to $60^{\circ}$, and a bimodal distribution is seen at intermediate distances from the tool. This behaviour mirrors the observations described in the images shown above, in that fine grains of a similar size to those in the nugget are first found to form heterogeneously in thin bands frequently associated with prior HAGBs/deformation bands, rather than by the continuous rotation of subgrains.

Continuous dynamic recrystallisation can occur at grain boundaries in some aluminium alloys containing high levels of solute, such as $\mathrm{Mg}$ and $\mathrm{Zn}$, by progressive lattice rotation $[24,45]$. This phenomenon has been summarised by Humphreys and Hatherly [25] and involves the rotation of subgrains adjacent to pre-existing grain boundaries within a local lattice orientation gradient that develops across the boundary. It occurs in Al-alloys where dislocation glide is restricted by solute drag and deformation is concentrated within a grain boundary mantle region. Bulges in boundaries formed by interaction with the substructure rotate to form new grains, resulting in a necklace of new subgrain-scale grains that decorate the original grain boundaries. In the enlarged images shown in Fig. 4(c), and at (ii) in 5(a), examples of wavy HAGBs can be seen, indicating that the temperature has increased sufficiently for local HAGB migration to occur and closer to the pin, bands of fine grains were seen to form along similar boundaries (Figs. 3 (b) and 5(b)). These new grains are of the same scale as those found in the nugget, but there is little evidence of rotation caused by a locally deforming grain mantle region and they appear to develop mainly by rearrangement of HAGBs formed by deformation bands in unstable original grains that split into diverging orientation.

During high strain deformation with an approximately constant strain path, even if no new HAGBs are formed by subdivision, geometry requires that the original HAGBs must increase in area [46] and reduce in spacing, forming elongated high aspect ratio fibrous grains, until ultimately the boundaries in the grain width direction will approach each other. This fact was first recognised by Humphreys [26,28] and McQueen $[23,27]$, who proposed that it could lead to a continuous dynamic recrystallisation process, termed geometric dynamic recrystallization (GDR). Classically, GDR occurs when the wavy boundaries present during hot deformation impinge, due to the compression of their spacing with strain causing the fibrous grains to break up into shorter lengths. This mechanism requires some boundary mobility, which allows wavy boundaries to develop and pinch off driven by the equilibration of boundary tensions. If GDR occurs when the boundary spacing approaches one subgrain wide, then the strain for the onset of GDR in plane strain compression can be predicted from

$\varepsilon_{\text {cri }}=\ln \left(Z^{1 / m} D_{0}\right)+C$,

where $Z$ is the Zener-Hollomon parameter, which determines the subgrain size for a given temperature and strain rate, $D_{0}$ is the original grain size and $m$ and $C$ are constants (see [47]). GDR is thus more likely at high temperatures and low strain rates, as encountered in torsion tests, when the subgrain size is large. In the presence of fine particles inhibiting grain growth, such as the $\mathrm{Al}_{3} \mathrm{Zr}$ dispersoids in the alloy studied, this mechanism can also result in a similar fine grain microstructure to that seen in weld nuggets. However, pinning particles will delay GDR to higher strains than predicted by Eq. (2), due to their effect on reducing boundary mobility [47].

The theoretical reduction in width of a homogeneously deforming grain in simple shear can be calculated from

$d=\frac{d_{0}}{\left(\sqrt{1+\gamma^{2}}\right)}$,

where $d_{0}$ is the initial grain width and $d$ is the grain width after a shear strain, $\gamma$ [48]. Eq. (3) has been plotted against strain in Fig. 12 for assumed initial grain widths of $20-200 \mu \mathrm{m}$, where $200 \mu \mathrm{m}$ is equivalent to the grain size seen in the parent plate and $20 \mu \mathrm{m}$ the approximate coarse deformation bandwidth, seen at the edge of the

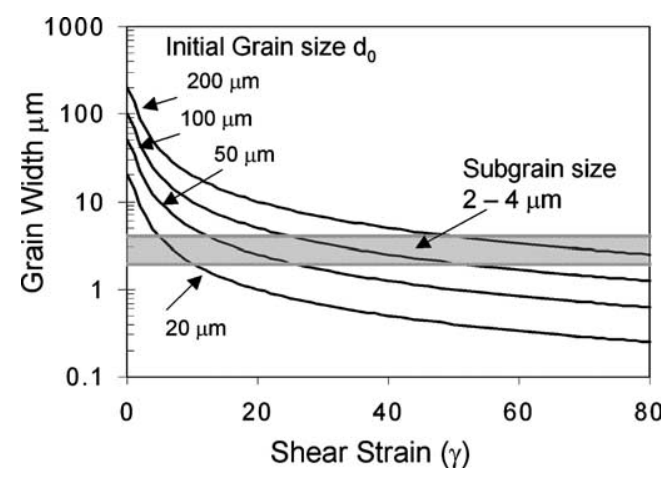

Fig. 12. The theoretically expected width of a grain deformed homogeneously in simple shear, for initial grain widths equivalent to 20-200 $\mu \mathrm{m}$, showing the strain for convergence with a subgrain size in the range $2-4 \mu \mathrm{m}$. 
tool deformation zone. The subgrain sizes on the edge of the nugget are within the range $2-4 \mu \mathrm{m}$. It can be seen from Fig. 12, that the grain width will easily converge with the subgrain size well within the strain range expected in the nugget region, particularly if the grains subdivide at an early stage. For example, for an original HAGB spacing of $\sim 20 \mu \mathrm{m}$, after forming coarse deformation bands, the grain width will converge with the subgrain size by an additional shear strain of $\sim 5$, or an effective strain of 3. In addition, on a local scale, convergence will occur at a wide range of strains depending on the stability of a given grain orientation.

Evidence of a GDR related process leading to the formation of the nugget grain structure is shown in Figs. 3 and 5. This occurs first heterogeneously from closely spaced HAGBs that develop at lower temperatures from deformation band boundaries, leading to bands of fine grains being formed. In Fig. 3(a) at location (i), finescale secondary deformation bands of alternating orientations can be seen to be forming within coarser primary deformation bands near the edge of the tools deformation zone. Coarser alternating deformation bands that already have HAGBs can also be seen in Fig. 5(a) at location (i) (misorientations in Fig. 5(c)). At location (ii) similar deformation bands can be seen as at location (i) in Fig. 3(a), but with a reduced spacing and higher misorientations as the strain increases closer to the tool (this behaviour can be seen quantitatively in the accumulative misorientation line scan in Fig. 3(d)). In the higher magnification view in Fig. 3(b) (which includes HAGBs $>15^{\circ}$ in misorientation as black lines) it can be seen that with increasing strain new HAGBs form along the fine deformation band borders, generating closely spaced segments of approximately parallel HAGBs (arrow (ii)). Further down the map, at location (iii) in Fig. 3(b), as the temperature increases local HAGB migration can occur and comparable features to the closely spaced deformation bands delineated by approximately parallel HAGBs can be seen to break up along their length into bands of subgrain-scale grains. A higher resolution, clearer example of this behaviour is shown in Fig. 13 from a similar position ahead of the tool and a similar behaviour can be seen in Fig. 5 at position (ii), highlighted in Fig. 5(b). This process initially occurs very heterogeneously as a function of the spacing of the deformation bands formed within an individual grain, which depends on their orientation and the local deformation conditions, and leads to a mixed microstructure of bands of recrystallised subgrain scale grains, and large fibrous grains of more stable orientation.

The volume fraction of the bands of new nugget scale grains rises with strain, and temperature due to the processes outlined above. However, the bands of fine grains will start to impinge when they are forced closer together by the increasing strain, which is also essentially a geometric effect. Eventually, on the nugget periphery,
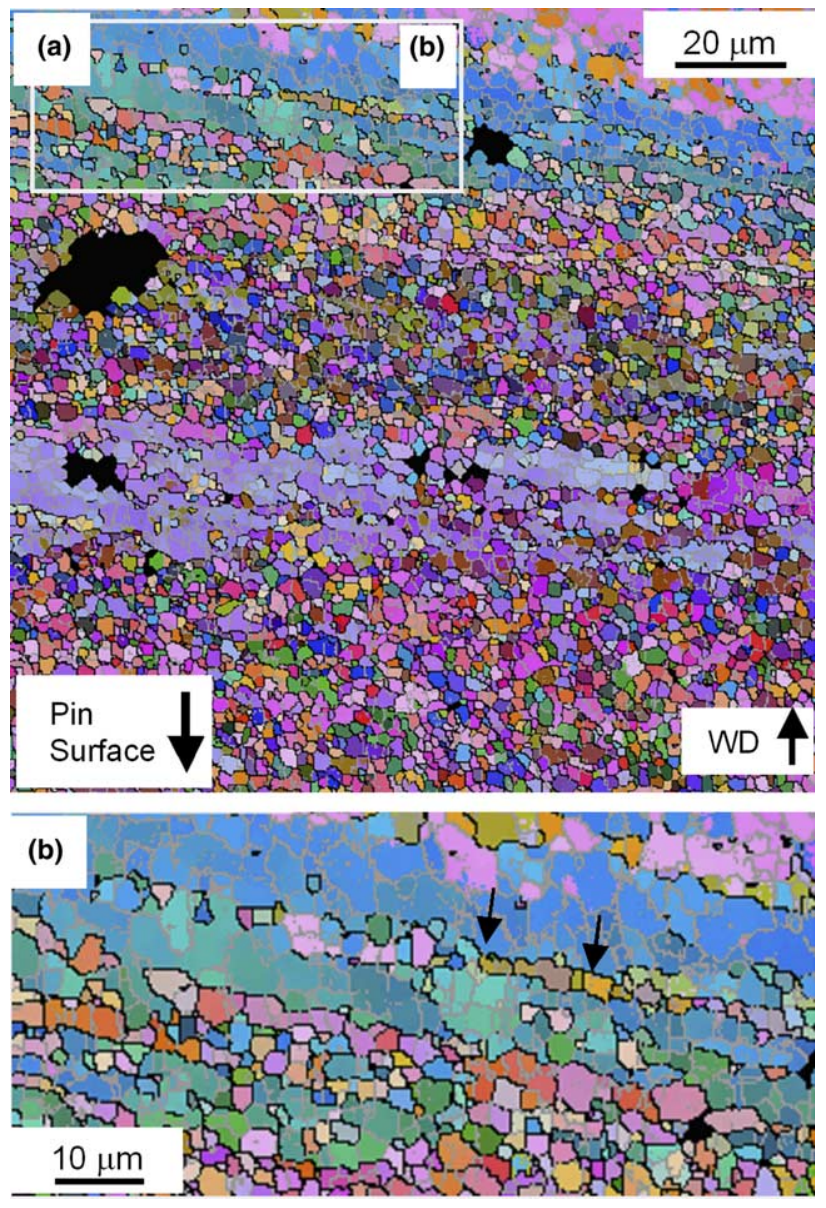

Fig. 13. (a) High resolution EBSD map from ahead of the tool showing the formation of bands of ultrafine nugget scale grains by a GDR related mechanism, highlighted at a higher magnification in (b).

only thin fibrous grains remain in a matrix of subgrainscale grains, which correspond to originally wider stable crystal volumes that do not readily subdivide, and have become compressed by the increasing strain. Ultimately, with further deformation, these surviving fragments also break up once their grain width reduces to the scale of the subgrain size and a fully nugget-like structure is formed.

Even though most of the original work on GDR was carried out using optical microscopy, the recrystallised grain structures formed at elevated temperatures close to the nugget boundary (e.g. Fig. 13) and within the nugget zone appear similar to those seen by McQueen and colleagues [23,27] in very-high strain hot torsion test, although the scale is finer and the boundaries do not appear as classically 'wavy' in the friction stir welds due to the higher strain rate and larger density of pinning particles. However, with closely spaced more planar lamellar HAGB boundaries, of around one subgrain wide, instability will still occur due to the surface tension of the transverse low angle boundaries when there is sufficient thermal energy for some local 
boundary migration. This encourages 'necking' or the pinching off of the parallel HAGBs. A similar behaviour has been seen on static annealing high aspect ratio thin lamellar grains formed by severe deformation at room temperature [31].

The grain refinement process therefore appears to be one driven by grain subdivision, and the geometric effects of strain, which reduce the overall high angle boundary spacing, but also involves thermally activated boundary migration and local continuous recrystallisation, mainly by GDR, which increases in importance as the temperature rises near to the tool. Grain subdivision is clearly an important aspect of the grain refinement process during friction stir welding. In this context it is interesting that it has recently been shown theoretically by Barnett and Montheillet [22] that grain subdivision will occur more readily in simple shear than under other deformation conditions, like plane strain compression. This behaviour is associated with the crystal rotation field that produces a metastable texture in simple shear. Taylor model predictions show that volumes that develop a small deviation from the ideal shear texture components will rotate away from the ideal orientation with increasing strain; i.e. subgrains that develop small misorientation differences within an individual grain will increase in misorientation, encouraging the splitting of a grain into diverging orientations. It is not yet clear how important this effect is to the rate of grain refinement in friction stir welding where, although simple shear is the predominant deformation mode, other minor strain components will affect the texture and crystal stability.

\section{Conclusions}

The grain structure development from interaction between the material and tool during friction stir welding has been directly observed by sectioning through a 'frozen' weld keyhole with the tool still in place. This has enabled the microstructure evolution leading to the development of the weld nugget grain structure to be studied with increasing strain and temperature, as fresh material encounters the deformation field surrounding the rotating pin. The grain refinement process is driven by grain subdivision, and the geometric effect of strain, which reduces the overall HAGB spacing, but also involves thermally activated local boundary migration that increases in importance as the temperature rises near to the tool. The higher temperature stages of this process are closely reminiscent of GDR seen in high strain hot torsion experiments. There is no evidence to support the idea of continuous dynamic recrystallisation by subgrain rotation.

At the cold periphery of the deformation zone ahead of the tool the parent grains first split into coarse pri- mary deformation bands. As the strain increases, the original grain boundaries and new deformation band boundaries reduce in separation due to the geometric requirements of the strain, forming elongated fibrous grains. Further grain subdivision continues to occur on a finer scale, probably encouraged by the dominant simple shear deformation mode. With increasing temperature closer to the tool, bands of fine nugget scale grains are first formed, from closely spaced parallel HAGBs that develop from finer scale deformation bands. This process involves local boundary migration driven by the surface tension of transverse low angle boundaries. A mixed microstructure develops consisting of a matrix of nugget scale grains containing high aspect ratio fibrous grains corresponding to more stable orientations. The bands of fine grains are forced closer together and increase in volume fraction with strain. Finally, the remaining fibrous grain fragments become unstable when they thin to subgrain dimensions and break up to form a full nugget-like microstructure comprised of low aspect ratio ultrafine grains. Following welding, the ultrafine grain nugget structure formed by this process becomes more equiaxed and coarsens slightly due to static annealing in the thermal wake of the tool.

The nugget material was found to have a strong ideal $\{112\}\langle 110\rangle$ texture or strong $B / \bar{B}$ ideal simple shear component, with the shear plane normal and shear direction aligned approximately perpendicular to and tangential with the flow lines in the nugget. Perturbations to this alignment were found to be responsible for the rings of orientation contrast seen in the nugget. The spacing of strong onion rings, or texture banding, in the nugget zone coincided with the pitch of a full revolution; however, weaker rings were seen every third of a rotation, caused by the flat faces machined on the pin.

\section{Acknowledgement}

The authors are grateful to K. J. Colligan of Concurrent Technologies Corp., Al, USA, for provision of the weld samples and for the EPSRC for funding this work through the Platform Grant, Thermomechanical processing of Light Alloys, GR/R69952/01.

\section{References}

[1] Threadgill PL, Friction stir welding - the state of the art. Bulletin 678, TWI, UK, 1999.

[2] Reynolds AP. Sci Technol Weld Join 2000;5:120.

[3] Seidel TU, Reynolds AP. Metall Mater Trans A 2001;32:2879.

[4] Colligan KJ. Welding Res Sup 2001;65:229.

[5] Askari A, Silling S, London B, Mahoney M. In: Proceedings: friction stir welding and processing, Indianapolis, IN, USA. Warrendale (PA): TMS; 2001. p. 43. 
[6] London B, Mahoney M, Bingel W, Calabrese M, Bossi RH, Waldron D. In: Proceedings: friction stir welding and processing II, San Diego, CA, USA. Warrendale (PA): TMS; 2003. p. 3.

[7] Heurtier P, Desrayaud C, Montheillet F. Mater Sci Forum 2002;396-402:1537.

[8] Xu X, Deng S. In: Proceedings: 4th int FSW symp, Park City, Utah, USA. Cambridge: TWI; 2003 (CD ROM).

[9] Norman AF, Brough I, Prangnell PB. Mater Sci Forum 2000;331-337:1713.

[10] Hassan Kh AA, Prangnell PB, Norman AF, Price DA, Williams SW. Sci Technol Weld Join 2003;8:257.

[11] Su J-Q, Nelson TW, Mishra R, Mahoney M. Acta Mater 2003;51:713.

[12] Jata KV, Semiatin SL. Scripta Mater 2000;43:743.

[13] Karlsen M, Tangen S, Hjelen J, Frigaard Ø, Grong Ø. In: Proceedings: 3rd int symp on friction stir welding, Kobe, Japan. Cambridge: TWI; 2001 (CD ROM).

[14] Karlsen M, Frigaard O, Hjelen J, Grong O, Norum H. Mater Sci Forum 2003;426-432:2861.

[15] Bingert JF, Fonda RW. In: Proceedings: 4th int FSW symp, Park City, Utah, USA. UK: TWI; 2003 (CD ROM).

[16] Hassan Kh AA, Wynne BP, Prangnell PB. In: Proceedings: 4th int FSW symp, Park City, Utah, USA. Cambridge: TWI; 2003 (CD ROM).

[17] Benavides S, Li Y, Murr LE. In: Proceedings: ultrafine grained materials, Nashville, TN, USA. Warrendale (PA): TMS; 2000. p. 155.

[18] Liu G, Murr LE, Niou C-S, McClure JC, Vega FR. Scripta Mater 1997;37:355.

[19] Murr LE, Liu G, McClure JC. J Mater Sci Lett 1997;16:1801.

[20] Humphreys FJ, Hatherly M. Recrystallization and related annealing phenomenon. Oxford: Pergamon Press; 2004. pp. 427-438.

[21] Blum W, Zhu Q, Merkel R, McQueen HJ. Mater Sci Eng A 1996;205:23.

[22] Barnett MR, Montheillet F. Acta Mater 2002;50:2285.

[23] McQueen HJ, Knustad O, Ryum N, Solberg JK. Scripta Metall 1985;19:73.

[24] Drury MR, Humphreys FJ. Acta Metall 1986;34:2259.

[25] Humphreys FJ, Hatherly M. Recrystallization and related annealing phenomenon. Oxford: Pergamon Press; 2004. pp. 438-441.
[26] Humphreys FJ. Proceedings: 6th int conf on strength of metals and alloys, Melbourne, Australia, vol. 2. Oxford, UK: Pergamon Press; 1982. p. 625.

[27] McQueen HJ, Solberg JK, Ryum N, Ness E. Philos Mag A 1989;60:473.

[28] Humphreys FJ, Drury MR. Proceedings: aluminium technology, London, UK, vol. 86. London: Institute of Metals; 1986. p. 191.

[29] Fonda RW, Bingert JF, Colligan KJ. Scripta Mater 2004;51:243.

[30] Ball E, Humphreys FJ. In: Proceedings: thermomechanical processing II, Stockholm, Sweden. Sweden: Swedish Society of Materials Technology; 1996. p. 184.

[31] Prangnell PB, Hayes JS, Bowen JR, Apps PJ, Bate PS. Acta Mater 2004;52:3193.

[32] Rhodes CG, Mahoney MW, Bingel WH, Calabrese M. Scripta Mater 2004;48:1451.

[33] Yan J, Yang B, Sutton MA, Reynolds AP, Ward J. In: Proceedings: 4th int FSW symp, Park City, Utah, USA. Cambridge: TWI; 2003 (CD ROM).

[34] Sutton MA, Yang B, Reynolds AP, Taylor R. Mater Sci Eng A 2002;323:160.

[35] Park SHC, Sato YS, Kokawa H. Metall Mater Trans A 2003;34:987.

[36] Colegrove PA, Shercliff HR. Sci Technol Weld Join 2004;9:345 \& 352.

[37] Kuhlmann-Wilsdorf D. Acta Mater 1999;47:1697.

[38] Schneider JA, Nunes AC. Metall Mater Trans B 2004;35:777.

[39] Dickerson TL, Shercliff HR. In: Proceedings: 4th int FSW symp, Park City, Utah, USA. Cambridge: TWI; 2003 (CD ROM).

[40] Field DP, Nelson TW, Hovanski Y, Jata KV. Metall Mater Trans A 2001;32:2869.

[41] Sato YS, Kokawa H, Ikeda K, Enomoto M, Jogan S, Hashimoto T. Metall Mater Trans A 2001;32:941.

[42] Montheillet F, Gilormini P, Jonas JJ. Acta Metall 1985;33:705.

[43] Tóth LS, Neale KW, Jonas JJ. Acta Metall 1989;37:2197.

[44] Pantleon W. Acta Mater 1998;46:451.

[45] Gardner KJ, Grimes R. Met Sci 1979;13:216.

[46] Bate PS, Hutchinson WB. Scripta Mater 2005;52:199.

[47] Gholinia A, Humphreys FJ, Prangnell PB. Acta Mater 2002;50:4461.

[48] Humphreys FJ, Prangnell PB, Bowen JR, Gholinia A, Harris C. Philos Trans Roy Soc Lond A 1999;357:1663. 